\title{
Digital methodology for analyzing the yield of sugar beet on leached chernozem of the Krasnodar Territory
}

\author{
Victoria Drozdova, Irina Buldykova*, Anastasia Kazakevich, and Vladimir Griguletsky \\ FSBEI HE Kuban State Agrarian University named after I. T. Trubilin, Kalinina Str., 13, 350044 \\ Krasnodar, Russia
}

\begin{abstract}
In the article, a mathematical expression is obtained that characterizes the effect of the doses of introduced fertilizers, the content of nutrients in the soil and their absorption by sugar beet plants on the yield of this crop. With the help of the developed mathematical model, the optimal values of the content of macronutrients in soil and plants are determined: nitrogen $\sim 21.81 \mathrm{mg} / \mathrm{kg}$ and $1.02 \%$; phosphorus $\sim 58.88 \mathrm{mg} / \mathrm{kg}$ and 0.33 $\%$; potassium $\sim 120.21 \mathrm{mg} / \mathrm{kg}$ and $1.33 \%$, respectively, which accumulate when introducing a complete fertilizer at a dose of $\mathrm{N}_{80} \mathrm{P}_{80} \mathrm{~K}_{80}$. This leads to the achievement of the maximum yield of root crops, which corresponds to the calculated value of this indicator $\approx$ of 56.94 and $64.6 \mathrm{t} / \mathrm{ha}$ and coincides with the experimental one $=57.9$ and $62.0 \mathrm{t} / \mathrm{ha}$, respectively, obtained in this variant. The introduced fertilizers containing boron contributed to a more intensive absorption of nitrogen, phosphorus and potassium by root crops. The use of trace elements causes a tendency to increase the yield of this crop.
\end{abstract}

\section{Introduction}

For the Russian Federation, sugar beet is the main raw material for sugar production. Over the past three years, the area of this crop sowings in the Russian Federation amounted to 1063.2 thousand. ha, including 191.8 thousand hectares in the Krasnodar Territory. The yield of root crops in the country on average was $380.4 \mathrm{c} /$ ha (gross harvest of 48.0 million tons), in the Krasnodar Territory $522.4 \mathrm{c} /$ ha, (gross harvest of 8.0 million tons) [3,4 ].

Fertilizers are an essential factor in stabilizing the yield of many agricultural crops, sugar beet is no exception, and their influence on the formation of this crop productivity is $26,8 \%[1,3,9]$.

\section{Materials and methods}

The analysis of experimental data was carried out on the basis of studies conducted in the stationary field experiment of the Department of Agrochemistry of the Kuban State

\footnotetext{
* Corresponding author: byldikova@yandex.ru
} 
Agrarian University, included in the "Register of long-term field experiments with fertilizers of the Russian Federation", in which the use of various types and norms of nitrogen, phosphorus and potassic fertilizers was studied.

The objects of the experiment were: leached chernozem and sugar beet of the Nero hybrid. The researches studied the effect of macro-and microelements on the yield of sugar beet root crops in the "soil-plant-fertilizer" system. The research methodology is described in previously published works $[3,4,7]$. The mathematical processing of the experimental data was carried out by the least squares method $[2,5,10]$.

\section{Results and discussion}

The introduced fertilizers had a positive effect on the studied indicators for the development of sugar beet, which led to an increase in the number of forms of nitrogen, phosphorus and potassium available for plant nutrition in the soil $[4,9]$.

Thus, in the phase of industrial ripeness of root crops, the level of mineral nitrogen on the fertilized variants remained on average $7.0 \mathrm{mg} / \mathrm{kg}$ higher than on the non-fertilized variant (Table 1). Its quantity has especially increased in the variants with unilateral nitrogen application $\left(\mathrm{N}_{40} \mathrm{P}_{0} \mathrm{~K}_{0}\right)$ and complete fertilizer $\left(\mathrm{N}_{80} \mathrm{P}_{80} \mathrm{~K}_{80}\right)$.

Table 1. Dependence of the content of mineral nitrogen, mobile phosphorus and potassium in the soil under sugar beet from the introduced fertilizers, $\mathrm{mg} / \mathrm{kg}$.

\begin{tabular}{|c|c|c|c|c|c|c|}
\hline Variant & Nitrogen & $\begin{array}{c}+/- \text { to } \\
\text { control }\end{array}$ & $\begin{array}{c}\text { Phosphor } \\
\text { us }\end{array}$ & $\begin{array}{c}+/- \text { to } \\
\text { control }\end{array}$ & $\begin{array}{c}\text { Potassiu } \\
\text { m }\end{array}$ & $\begin{array}{c}+/- \text { to } \\
\text { control }\end{array}$ \\
\hline $\begin{array}{c}\text { Control } \\
\text { (no fertilizers) }\end{array}$ & 17,2 & - & 37,8 & - & 103,1 & - \\
\hline $\mathrm{N}_{80} \mathrm{P}_{0} \mathrm{~K}_{0}$ & 26.9 & 9.7 & 43.1 & 5.3 & 107.2 & 4.1 \\
\hline $\mathrm{N}_{0} \mathrm{P}_{80} \mathrm{~K}_{0}$ & 22.3 & 5.1 & 60.7 & 22.9 & 113.7 & 10.6 \\
\hline $\mathrm{N}_{0} \mathrm{P}_{0} \mathrm{~K}_{80}$ & 21.8 & 4.6 & 49.4 & 11.6 & 139.3 & 36.2 \\
\hline $\mathbf{N}_{80} \mathrm{P}_{80} \mathrm{~K}_{80}$ & 26.3 & 9.1 & 63.8 & 26.0 & 129.8 & 26.7 \\
\hline $\mathrm{N}_{40} \mathrm{P}_{40} \mathrm{~K}_{40}$ & 22.5 & 5.3 & 48.8 & 11.0 & 112.0 & 8.9 \\
\hline $\mathrm{N}_{120} \mathrm{P}_{120} \mathrm{~K}_{120}$ & 25.3 & 8.1 & 64.3 & 26.5 & 159.5 & 56.4 \\
\hline
\end{tabular}

The data in Table 1 show that the content of mobile phosphorus increased on the fertilized variants by an average of $17.2 \mathrm{mg} / \mathrm{kg}$ compared to the control one. The best variants were $\mathrm{N}_{0} \mathrm{P}_{80} \mathrm{~K}_{0}$ and $\mathrm{N}_{80} \mathrm{P}_{80} \mathrm{~K}_{80}$. The amount of available potassium in the soil was higher in the variants with the use of fertilizers by $23.8 \mathrm{mg} / \mathrm{kg}$. The highest residue of this element was in the variants $\mathrm{N}_{0} \mathrm{P}_{0} \mathrm{~K}_{80}$ and $\mathrm{N}_{120} \mathrm{P}_{120} \mathrm{~K}_{120}$.

An increase in the level of soil nutrition of sugar beet due to the use of mineral fertilizers led to an increase in the absorption of nutrients by plants (Table 2).

Table 2. The effect of mineral fertilizers on the content of nitrogen, phosphorus and potassium in sugar beet root crops, $\%$ of dry weight.

\begin{tabular}{|l|c|c|c|c|c|c|}
\hline \multicolumn{1}{|c|}{ Variant } & $\begin{array}{c}\text { Nitroge } \\
\mathrm{n} \\
(\mathrm{N})\end{array}$ & $\begin{array}{c}+/- \text { to } \\
\text { control }\end{array}$ & $\begin{array}{c}\text { Phosphorus } \\
\left(\mathrm{P}_{2} \mathrm{O}_{5}\right)\end{array}$ & $\begin{array}{c}+/- \text { to } \\
\text { control }\end{array}$ & $\begin{array}{c}\text { Potassium } \\
\left(\mathrm{K}_{2} \mathrm{O}\right)\end{array}$ & $\begin{array}{c}+/- \text { to } \\
\text { control }\end{array}$ \\
\hline $\begin{array}{l}\text { Control } \\
\text { (no fertilizers) }\end{array}$ & 0,94 & - & 0,25 & - & 1,09 & - \\
\hline $\mathrm{N}_{80} \mathrm{P}_{0} \mathrm{~K}_{0}$ & 1.10 & 0.16 & 0.29 & 0.04 & 1.19 & 0.10 \\
\hline $\mathrm{N}_{0} \mathrm{P}_{80} \mathrm{~K}_{0}$ & 0.97 & 0.03 & 0.29 & 0.04 & 1.10 & 0.01 \\
\hline $\mathrm{N}_{0} \mathrm{P}_{0} \mathrm{~K}_{80}$ & 0.95 & 0.01 & 0.26 & 0.01 & 1.26 & 0.17 \\
\hline $\mathrm{N}_{80} \mathrm{P}_{80} \mathrm{~K}_{80}$ & 1.10 & 0.16 & 0.31 & 0.06 & 1.29 & 0.20 \\
\hline $\mathrm{N}_{40} \mathrm{P}_{40} \mathrm{~K}_{40}$ & 0.98 & 0.04 & 0.27 & 0.02 & 1.20 & 0.11 \\
\hline $\mathrm{N}_{120} \mathrm{P}_{120} \mathrm{~K}_{120}$ & 1.13 & 0.19 & 0.32 & 0.07 & 1.29 & 0.20 \\
\hline
\end{tabular}


The data in Table 2 show that the amount of nitrogen in sugar beet root crops increased by an average of $0.1 \%$, phosphorus by $0.04 \%$ and potassium by $0.13 \%$ due to the use of fertilizers. Very effective results were obtained with a balanced mineral nutrition of plants in the variant $\mathrm{N}_{80} \mathrm{P}_{80} \mathrm{~K}_{80}$.

Experiments have shown that the yield of sugar beet root crops has increased due to the use of fertilizers (Table 3).

Table 3. The yield of sugar beet root crops depending on mineral fertilizers.

\begin{tabular}{|l|c|c|c|c|c|}
\hline \multirow{2}{*}{ Variant } & \multicolumn{4}{|c|}{ Yield by year, t/ha } & \multirow{2}{*}{$\begin{array}{c}\text { Increase, } \\
\text { t } / \mathrm{ha}\end{array}$} \\
\cline { 2 - 5 } & 2012 & 2013 & 2014 & average & - \\
\hline $\begin{array}{l}\text { Control } \\
\text { (no fertilizers) }\end{array}$ & 34.6 & 53.6 & 46.5 & 44.9 & \\
\hline $\mathrm{N}_{80} \mathrm{P}_{0} \mathrm{~K}_{0}$ & 42.9. & 60.0 & 51.0 & 51.3 & 6.4 \\
\hline $\mathrm{N}_{0} \mathrm{P}_{80} \mathrm{~K}_{0}$ & 39.3 & 69.4 & 49.3 & 52.7 & 7.8 \\
\hline $\mathrm{N}_{0} \mathrm{P}_{0} \mathrm{~K}_{80}$ & 47.9 & 70.2 & 48.2 & 55.4 & 10.5 \\
\hline $\mathrm{N}_{80} \mathrm{P}_{80} \mathrm{~K}_{80}$ & 57.9 & 71.7 & 56.5 & 62.0 & 17.1 \\
\hline $\mathrm{N}_{40} \mathrm{P}_{40} \mathrm{~K}_{40}$ & 50.3 & 64.6 & 52.2 & 55.7 & 10.8 \\
\hline $\mathrm{N}_{120} \mathrm{P}_{120} \mathrm{~K}_{120}$ & 61.4 & 70.7 & 58.0 & 63.4 & 18.5 \\
\hline $\mathrm{LSDD}_{05}$ & 6.7 & 8.5 & 7.4 & 7.5 & \\
\hline
\end{tabular}

The data in Table 3 show that the yield of root crops on fertilized variants increased by $11.9 \mathrm{t} / \mathrm{ha}$ or $26.4 \%$ on average according to the experiment. The greatest increase in yield was obtained on the variants using $\mathrm{N}_{80} \mathrm{P}_{80} \mathrm{~K}_{80}$ and $\mathrm{N}_{120} \mathrm{P}_{120} \mathrm{~K}_{120}$, but the best sugar content was when using $\mathrm{N}_{80} \mathrm{P}_{80} \mathrm{~K}_{80}(18.7 \%)$, which indicates that it is not advisable to increase the dose of fertilizers to a high level.

Sugar beet plants during the growing season need not only nitrogen, phosphorus and potassium, but also trace elements, mostly boron, for the normal course of physiological and biochemical processes [3].

Experiments have shown that the treatment of sugar beet plants with fertilizer solutions with trace elements provided a more intensive absorption of macronutrients (Table 4).

Table 4. Nitrogen, phosphorus and potassium content in sugar beet root crops, $\%$ of dry weight.

\begin{tabular}{|c|c|c|c|c|c|c|}
\hline \multirow{2}{*}{ Variant } & \multicolumn{6}{|c|}{ The content of nutrients in the plant, \% } \\
\cline { 2 - 7 } & $\mathrm{N}$ & $\begin{array}{c}+/- \\
\text { to control }\end{array}$ & $\mathrm{P}_{2} \mathrm{O}_{5}$ & $\begin{array}{c}+/- \\
\text { to control }\end{array}$ & $\mathrm{K}_{2} \mathrm{O}$ & $\begin{array}{c}+/- \\
\text { to control }\end{array}$ \\
\hline $\begin{array}{c}\mathrm{N}_{80} \mathrm{P}_{80} \mathrm{~K}_{80}- \\
\text { background }\end{array}$ & 1.03 & - & 0.28 & - & 1.12 & - \\
\hline Background $+\mathrm{Zn}$ & 1.14 & 0.09 & 0.29 & 0.01 & 1.20 & 0.08 \\
\hline Background $+\mathrm{B}$ & 1.22 & 0.19 & 0.34 & 0.06 & 1.32 & 0.20 \\
\hline Background $+\mathrm{Cu}$ & 1.18 & 0.16 & 0.30 & 0.02 & 1.22 & 0.10 \\
\hline
\end{tabular}

The results showed that the accumulation of nitrogen in root crops increased by an average of $0.15 \%$, an increase from 0.09 to $0.19 \%$ relative to the background. The phosphorus content ranged from $0.29-0.34 \%$ and increased by $0.03 \%$ on average. The potassium content increased by $1.20-1.32 \%$ and on average exceeded the background by $0.13 \%$. Boric micro-fertilizer had the maximum effect on all indicators.

The applied trace elements, increasing the absorption of nitrogen, phosphorus and potassium by plants, contributed to the formation of a greater yield of root crops (Table 5). 
Table 5. The yield of sugar beet root crops with non-root fertilization of plants with micro-fertilizers.

\begin{tabular}{|c|c|c|c|c|c|}
\hline \multirow{2}{*}{ Variant } & \multicolumn{3}{|c|}{ Yield by year, $\mathrm{t} / \mathrm{ha}$} & \multirow{2}{*}{ Average } & Increase \\
\cline { 2 - 3 } & 2012 & 2013 & 2014 & & $\mathrm{t} / \mathrm{ha}$ \\
\hline $\begin{array}{c}\mathrm{N}_{80} \mathrm{P}_{80} \mathrm{~K}_{80}- \\
\text { backgground }\end{array}$ & 57.9 & 71.7 & 56.5 & 62.0 & - \\
\hline Background $+\mathrm{Zn}$ & 58.6 & 72.2 & 56.9 & 62.6 & 0.6 \\
\hline Background $+\mathrm{B}$ & 60.9 & 74.2 & $59 . .6$ & 64.9 & 2.9 \\
\hline Background $+\mathrm{Cu}$ & 59.1 & 73.0 & 58.0 & 63.4 & 1.4 \\
\hline LSD & 0.53 & 0.52 & 0.47 & 0.51 & \\
\hline
\end{tabular}

Under the influence of micro-fertilizers, there is a tendency to increase the amount of crop. On average, this indicator increased by $1.5 \mathrm{t} / \mathrm{ha}$.

Mathematical processing. In contrast to the most popular methods of processing of research results (regression) with a single factor [5], a mathematical model of multiple nonlinear correlation was used for the data under consideration [2, 6]. In [6], it is proposed to build mathematical models for the production function of the efficiency of fertilizer use in the form of polynomials of the following type:

$$
Y=a_{0}+a_{1} N+a_{2} N^{2}+a_{3} P+a_{4} P^{2}+a_{5} N P
$$

(ratio (IV-10), p. 146, [6]),

where $N, P$ are the doses of nitrogen and phosphorus, respectively,

or:

$$
Y_{1}=a_{0}+a_{1} N+a_{2} N^{2}+a_{3} P+a_{4} P^{2}++a_{5} K+a_{6} K^{2}+a_{7} N P+a_{8} N K+a_{9} P K
$$

(ratio (IV-11), p. 146, [6]),

$N, P, K$ - doses of nitrogen, phosphorus, and potassium, respectively, or:

$Y_{2}=a_{0}+a_{1} N^{0,5}+a_{2} N+a_{3} P^{0,5}+a_{4} P+a_{5} K^{0,5}+a_{6} K+a_{7}(N P)^{0,5}+a_{8}(N K)^{0,5}+a_{9}(P K)^{0,5}$

(ratio (IV-12), p. 147, [6]) and others $a_{0}, a_{1}, \ldots, a_{9}$ - constant coefficients.

It is also noted in [6] that "the processing of actual experimental data to determine the numerical values of parameters $a_{0}, a_{1}, \ldots, a_{9}$, the sum of regression squares and the residual sum of squares for each of these models is carried out, as usual, by the least squares method.

Calculations of equations with 10 components, especially for fractional powers of variables, are lengthy and require the use of a computer."

The following functional dependence is taken as a mathematical model that determines the yield of sugar beet:

$$
\mathrm{P}(x, y, z)=a_{0}+a_{1} x+a_{2} y+a_{3} z+b_{1} x^{2}+b_{2} y^{2}+b_{3} z^{2}+c_{1} x y+c_{2} x z+c_{3} y z .
$$

According to the ratio (1), the yield $\left(\mathrm{N}_{i}\right)$ of sugar beet is determined by the amount of nitrogen $\left(x_{i}\right)$, phosphorus $\left(y_{i}\right)$ and potassium $\left(z_{i}\right)$ introduced in the form of fertilizers and the content of macronutrients in the soil in the amount of $\mathrm{mg}$ per $1 \mathrm{~kg}$ of soil; $a_{0}, a_{1}, a_{2}, \ldots, c_{3}$. - constant coefficients determined by the least squares' method based on experimental data.

The values of the ten constant coefficients $a_{0}, a_{1}, a_{2}, a_{3}, b_{1}, b_{2}, b_{3}, c_{1}, c_{2}, c_{3}$ are found from the condition of the minimum of the sum of the squares of deviations of experimental data of $\mathrm{P}_{0}\left(x_{i}, y_{i}, z_{i}\right)$ from the calculated values $\mathrm{P}_{\text {of }}\left(x_{i}, y_{i}, z_{i}\right)$, determined by the formula (1) and, therefore, we can write the ratio: 


$$
\Delta\left(x_{i}, y_{i}, z_{i}\right)=\sum_{i=1}^{n}\left[\mathrm{P}_{0}\left(x_{i}, y_{i}, z_{i}\right)-\mathrm{P}_{P}\left(x_{i}, y_{i}, z_{i}\right)\right]^{2} \rightarrow \min ,
$$

$n$ - the number of experiments (trials) $-\Delta_{i}$ - the sum of the squares of the deviations of the experimental data $\mathrm{P}_{0}\left(x_{i}, y_{i}, z_{i}\right)$ from the calculated values $\mathrm{P}_{p}\left(x_{i}, y_{i}, z_{i}\right)$.

Thus, the values of these unknown constants are found from a system of ten algebraic linear equations of the form:

$$
\left\{\begin{array}{l}
\frac{\partial \Delta}{\partial a_{0}}=2 \Sigma\left[\mathrm{P}_{0}\left(x_{i}, y_{i}, z_{i}\right)-\mathrm{P}_{P}\left(x_{i}, y_{i}, z_{i}\right)\right](1)=0 \\
\frac{\partial \Delta}{\partial a_{1}}=2 \Sigma\left[\mathrm{P}_{0}\left(x_{i}, y_{i}, z_{i}\right)-\mathrm{P}_{P}\left(x_{i}, y_{i}, z_{i}\right)\right]\left(x_{i}\right)=0 \\
\left.\cdot \cdot \cdot \cdot \cdot \cdot \cdot \cdot \cdot \cdot \cdot \cdot \cdot \cdot \cdot \cdot \cdot \cdot \cdot \cdot \cdot \cdot \cdot \cdot \cdot y_{i} z_{i}\right)=0 \\
\frac{\partial \Delta}{\partial c_{3}}=2 \Sigma\left[\mathrm{P}_{0}\left(x_{i}, y_{i}, z_{i}\right)-\mathrm{P}_{P}\left(x_{i}, y_{i}, z_{i}\right)\right]
\end{array}\right.
$$

(the summation index $(i)$ is omitted for brevity).

In the expanded form, the equations of the system (3) have the form:

$$
\begin{aligned}
& a_{0} n+a_{1} \sum x_{i}+a_{2} \sum y_{i}+a_{3} \sum z_{i}+b_{1} \sum x_{i}^{2}+b_{2} \sum y_{i}^{2}+ \\
& +b_{3} \sum z_{i}^{2}+c_{1} \sum x_{i} y_{i}+c_{2} \sum x_{i} z_{i}+c_{3} \sum y_{i} z_{i}=\sum \mathrm{P}_{i}, \\
& a_{0} \sum x_{i}+a_{1} \sum x_{i}^{2}+a_{2} \sum x_{i} y_{i}+a_{3} \sum x_{i} z_{i}+b_{1} \sum x_{i}^{3}+b_{2} \sum x_{i} y_{i}^{2}+ \\
& +b_{3} \sum x_{i} z_{i}^{2}+c_{1} \sum x_{i}^{2} y_{i}+c_{2} \sum x_{i}^{2} z_{i}+c_{3} \sum x_{i} y_{i} z_{i}=\sum x_{i} \mathrm{P}_{i}, \\
& a_{0} \sum y_{i} z_{i}+a_{1} \sum x_{i} y_{i} z_{i}+a_{2} \sum y_{i}^{2} z_{i}+a_{3} \sum y_{i} z_{i}^{2}+b_{1} \sum x_{i}^{2} y_{i} z_{i}+b_{2} \sum y_{i}^{3} z_{i}+ \\
& +b_{3} \sum y_{i} z_{i}^{3}+c_{1} \sum x_{i} y_{i}^{2} z_{i}+c_{2} \sum x_{i} y_{i} z_{i}^{2}+c_{3} \sum y_{i}^{2} z_{i}^{2}=\sum y_{i} z_{i} \mathrm{P}_{i} .
\end{aligned}
$$

To solve the considered system (4), any known method can be used, for example, the Gauss or Kramer method.

After the values of the constant coefficients $a_{0}, a_{1}, a_{2}, a_{3}, b_{1}, b_{2}, b_{3}, c_{1}, c_{2}, c_{3}$ are determined, the function of the three arguments $\mathrm{P}(x, y, z)$ of the relation (1) allows to find the "critical" (optimal) values of the parameters $x_{c r}, y_{c r}, z_{c r}$ from the system of three algebraic equations:

$$
\begin{gathered}
\frac{\partial \mathbf{P}}{\partial x}=0, \quad \frac{\partial \mathbf{P}}{\partial y}=0, \quad \frac{\partial \mathbf{P}}{\partial z}=0 \\
\text { or, in the expanded form: } \\
\left\{\begin{array}{l}
a_{1}+2 b_{1} x_{c r}+c_{1} y_{c r}+c_{2} z_{c r}=0 \\
a_{2}+2 b_{2} y_{c r}+c_{1} x_{c r}+c_{3} z_{c r}=0 \\
a_{3}+2 b_{3} z_{c r}+c_{3} y_{c r}+c_{2} x_{c r}=0
\end{array}\right.
\end{gathered}
$$

To reduce the amount of computational work and improve the accuracy of calculations, it is advisable to convert the experimental data to dimensionless units: the values of the first row are taken as a conditional unit, and the subsequent values are determined as a quotient of the dimensional data to the values of the first row. 
Based on the obtained dimensionless data, the values of the coefficients of the system of ten linear algebraic equations (4) were determined, which can be written as:

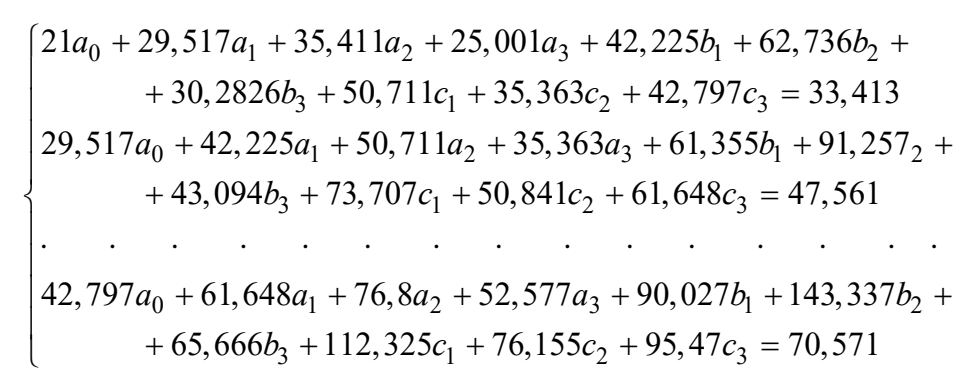

The values of the coefficients are determined by the Gauss method:

$$
\begin{aligned}
& a_{0}=-2,902 ; a_{1}=-2,318 ; a_{2}=1,737 ; a_{3}=6,686 ; \\
& b_{1}=0,155 ; b_{2}=-1,495 ; b_{3}=-4,579 ; \\
& c_{1}=0,626 ; c_{2}=0,99 ; c_{3}=2,179 .
\end{aligned}
$$

Considering the obtained values, according to the formula (1), we can write the ratio that determines the yield of sugar beet as a function $\left(\mathrm{N}_{\mathrm{p}}\right)$ of the dose of nitrogen $(x)$, the dose of phosphorus $(y)$ and the dose of potassium $(z)$ in dimensionless units:

$$
\begin{aligned}
\mathrm{P}(x, y, z)= & -2,902+2,318 x+1,737 y+6,686 z+0,155 x^{2}-1,495 y^{2}- \\
& -4,579 z^{2}+0,626 x y+0,99 x z+2,179 y z
\end{aligned}
$$

Considering the conditions (5), the values of the coefficients $a_{0}, a_{1}, a_{2}, a_{3}, b_{1}, b_{2}, b_{3}, c_{1}, c_{2}, c_{3}$, it is possible to create a system of three linear algebraic equations (6) to determine the "optimal" values of macronutrients: $x_{\mathrm{cr}}, y_{\mathrm{cr}}, z_{\mathrm{cr}}$ in the form:

$$
\left\{\begin{array}{c}
2,318-0,31 x_{c r}-0,626 y_{c r}-0,99 z_{c r}=0 \\
-1,737-0,626 x_{c r}+2,991 y_{c r}-2,179 z_{c r}=0 \\
-6,686-0,99 x_{c r}-2,179 y_{c r}-9,158 z_{c r}=0 .
\end{array}\right.
$$

The solution of this system is the values:

$$
x_{c r}=1,268, y_{c r}=1,558, z_{c r}=1,166 .
$$

For these values of the arguments, we find the highest yield value in dimensionless units:

$$
\mathrm{P}_{p}\left(x_{c r}, y_{c r}, z_{c r}\right)=1,646
$$

In dimensional units, you can find the values:

$$
\begin{aligned}
& x_{c r}=1,268 \times 17,2 \approx 21,81(\mathrm{mg} / \mathrm{kg}) \quad(\text { Nitrogen }), \\
& y_{c r}=1,558 \times 37,8 \approx 58,89(\mathrm{mg} / \mathrm{kg}) \quad \text { (Phosphorus), } \\
& z_{c r}=1,166 \times 103,1 \approx 120,21(\mathrm{mg} / \mathrm{kg}) \quad(\text { Pottasium}),
\end{aligned}
$$

and, therefore, the maximum yield is equal to: 


$$
\mathrm{P}_{\max }=1,646 \times 34,6 \approx 56,95(\mathrm{t} / \mathrm{ha}) .
$$

In the same way, based on experimental data, a mathematical model of the content of the considered macronutrients in root crops was derived and their optimal values were calculated (the initial data were not converted to dimensionless units).

$$
\begin{gathered}
\mathrm{P}(x, y, z)=-1554,575,+2515,99 x-2897,27 y+1218,119 z-1182,554 x^{2}- \\
-2090,028 y^{2}+222,913 z^{2}+5540,529 x y-1440,106 x z-1450,436 y z \\
x_{c r}=1,02 \% \text { (Nitrogen), } \\
y_{c r}=0,327 \% \text { (Phosphorus), } \\
z_{c r}=1,329 \% \text { (Pottasium), } \\
\mathrm{P}_{P}\left(x_{c r}, y_{c r}, z_{c r}\right)=64,592(\mathrm{t} / \mathrm{ha}) .
\end{gathered}
$$

The calculated values fully correspond to the experimental data.

A mathematical model of the effect of fertilizing of plants with micro-fertilizers on the yield and the content of macronutrients in root crops was also derived

$$
\begin{gathered}
\mathrm{P}(x, y, z)=40,222-166,676 x-238,084 y+256,729 z-144,675 x^{2}+ \\
+1855,01 y^{2}+565,46 z^{2}+3028,251 x y-353,872 x z-3800,8 y z \\
x_{c r}=1,498 \% \text { (Nitrogen), } \\
y_{c r}=0,373 \% \text { (Phosphorus), } \\
z_{c r}=1,495 \% \text { (Pottasium), } \\
\mathrm{P}_{P}\left(x_{c r}, y_{c r}, z_{c r}\right)=62,882(\mathrm{t} / \mathrm{ha}) .
\end{gathered}
$$

Recent calculations have shown that the accumulation of nitrogen, phosphorus and potassium in root crops is significantly influenced by the use of boric micro-fertilizer. However, the obtained optimal value $\mathrm{P}_{p}\left(x_{c r}, y_{c r}, z_{c r}\right)$ indicates that trace elements have a negligible effect on yield.

In general, the results of the experiment indicate that the application of mineral fertilizers at a dose of $\mathrm{N}_{80} \mathrm{P}_{80} \mathrm{~K}_{80}$ leads to the accumulation of the optimal amount of nutrients for the development of sugar beet plants in the soil, which ensures the maximum yield of root crops in the range from 57.9 to $62.0 \mathrm{t} / \mathrm{ha}$.

\section{Conclusion}

1. The analysis of the obtained experimental data showed that the level of nutrients in the soil increases with the use of mineral fertilizers, which leads to an increase in their absorption by sugar beet plants.

2. On the basis of the provisions of the least squares the mathematical model in the form of a polynomial of three variables was determined, which determines the dependence of sugar beet yield on the dose of nitrogen $(x), \mathrm{p}(u)$ and potassium $(z)$; the optimal values of the dose of macronutrients: nitrogen $-21,81 \mathrm{mg} / \mathrm{kg}$; phosphorus $-58,89 \mathrm{mg} / \mathrm{kg}$, potassium $-120,21 \mathrm{mg} / \mathrm{kg}$ and the corresponding maximum value of the estimated yield $\approx$ of 56.95 $\mathrm{t} / \mathrm{ha}$, which corresponds well to the experiment value $-57,9 \mathrm{t} / \mathrm{ha}$.

3. The mathematical model of the content of macronutrients in roots were found and their optimal values were determined: nitrogen - 1,02\%; phosphorus - $0.33 \%$ and 
potassium $-1.33 \%$, at which the estimated maximum yield is $64.6 \mathrm{t} / \mathrm{ha}$, corresponding to an experiment average value of $62.0 \mathrm{t} / \mathrm{ha}$, which is obtained in the variant with the introduction of $\mathrm{N}_{80} \mathrm{P}_{80} \mathrm{~K}_{80}$.

4. The effect of fertilizing plants with boric micro-fertilization led to an increase in the absorption of nutrients by sugar beet plants, which corresponds to the content of macronutrients in root crops: nitrogen $-1.49 \%$; phosphorus $-0.37 \%$, potassium $-1.49 \%$, with a yield of $62.9 \mathrm{t} / \mathrm{ha}$, which was obtained in the background variant.

\section{References}

1. I. A. Buldykova, A. Kh. Sheudzhen, Polytem. set. electron. scientific journal. of KubSAU (Scientific Journal) KubSAU, 04 (098) (2014) http://ej.kubagro.ru/2014/04/

2. V.G. Griguletsky, Mathematical processing of agronomic and zootechnical observations, 435 (Krasnodar, KubSAU named after I. T. Trubilin, 2021)

3. V.V. Drozdova, I.A. Buldykova, Proceedings of the Kuban SAU 77, 94-100 (2019)

4. V.V. Drozdova, I A. Buldykova, A.Kh. Sheudzhen, Fertility 1 (106), 8-11 (2019)

5. V.V. Drozdova, N.E. Redina, KubSAU 111 (2015) http://ej.kubagro.ru/2015/07/pdf /107.pdf

6. V.N. Peregudov, The method of least squares and its application in research, 340 (M., Statistics, 1965)

7. V.N. Peregudov, Planning of multifactorial field experiments with fertilizers and mathematical processing of their results, 183 (Moscow: Kolos, 1978)

8. O.A. Gutorova, A.K. Sheudzhen, H.D. Hurum, IOP Conference Series: Earth and Environmental Science, 659(1), 012122 (2021)

9. I. Shabanova, N. Neshchadim, K. Gorpinchenko, A. Boyko, E3S Web of Conferences 203, $02012(2020)$

10. F. Eulenstein, M. Tauschke, M. Lana, ... R. Schindler, H. Drechsler, Environmental Science and Engineering (Subseries: Environmental Science), 202979, 263-273 (2014)

11. Henry Lewis Rietz, Mathematical statistics, Mathematical Association of America, (2013), https://doi.org/10.5948/UPO9781614440031 